\title{
The Diagnosis of Conflict Management Within the Organization
}

\author{
Hanafiah $^{1}$, M Heikal $^{2}$, Wahyuddin Albra ${ }^{2}$, Dahlan Abdullah ${ }^{3}$, Damanhur Abbas ${ }^{4}$, Henry \\ Aspan $^{5}$ and Syarkani ${ }^{6}$ \\ \{hanafiah.1969.mpd@gmail.com\} \\ ${ }^{1}$ Department of Historical Education, Universitas Samudra, Langsa, Indonesia \\ ${ }^{2}$ Department of Management, Universitas Malikussaleh, Aceh, Indonesia \\ ${ }^{3}$ Department of Informatics, Universitas Malikussaleh, Aceh, Indonesia \\ ${ }^{4}$ Department of Islamics Economics, Universitas Malikussaleh, Aceh, Indonesia \\ ${ }^{5}$ Department of Management, Universitas Pembangunan Panca Budi, Medan, Indonesia \\ ${ }^{6}$ Department of Early Childhood Education, Universitas Almuslim, Bireuen, Indonesia
}

\begin{abstract}
The presence of the conflict within the organization is inevitable. The conflicts in the organization can occur among individuals, for instance, conflicts betweena leader and staff members, an individual and a group, and a particular group and the other. In fact, not all conflicts could harm the organization; it is widely believed that well-organized and controlled conflicts could inevitably benefit the organization as a unity. The discussion about conflicts within the oragiziation is strictly needed since conflict will unavoidably arise in every organization. Thus, in order to solve this issue, we need to understand how to diagnose and manage the conflicts properly so that we can cope with the conflict well
\end{abstract}

Keywords: Conflict Management, Organization

\section{INTRODUCTION}

A conflict tends to emerge in any groups and organizations.It is strongly related to the feelings of human beings, viz. negeleted, underrated, unappreciated, abondened, and annoyed due to disharmony during the work. The conflict itself derived from the Latin verb configure, which means to hit each other. Sociologically, conflict is defined as a process between two or more people, or even a group of people who is trying to get rid of the other parties through destroying and making them powerless.

Various feelings already mentioned above could cause outrage, which would potentially lead to conflict at anytime. Such circumstances will affect an individual performance and productivity in carrying out the organizational activities. The emergence of the conflict within the organization is caused by many factors such as state of the art technology, intense competition, cultural differences, value changes, and other individual personalities.

Handoko argued that organizational conflict is a mismatch between two or more members of the group, or groups of organizations arising due to the fact that they have to share limited resources or work activities; or simply because they have different status, purpose, and perception [1]. 
Based on above definition, it would then be related to the one of the most significant parts in the organization, which is how a leader has to understand the factors causing conflicts among both individuals and groups. A proper understanding about those issues would make it easier for a leader to overcome the conflicts.

A leader should be able to harmonize a different group of people, bring together various interests, and utilize all capabilities in order to achieve a goal. As stated by Robbins [2], "An organization is a consciously coordinated social entity, with a relatively identifiable boundary, that function on a relatively continuous basis to achieve a command goal or set of goals."The pattern of interaction in the organization is supposed to be regulated in order to obtain the balance and harmony among members, and avoid redundancy. Furthermore, a leader also has to ensure the critical tasks accomplished well and an organization should have a relative and identifiable boundary.

Restrictions could be changed in a certain period of time, but a real restriction should exist in order to differentiate the various interests. Conflict management is crucial; it is simply because any changes within an organization tend to lead to a conflict. For instance, it can be seen from Samudra University, during its transition period, there are a lot of institutional changes found in the university. It, then, alters not only the structure and personnel of the university but also impacts the organizational and personal relationships, which could potentially lead to a conflict.If the conflicts are not managed properly and thoroughly, it will disturb the balance of the resources and the relationships between the involved people.

The failure to overcome the conflict could lead to harmful consequences. Conflict can destroy the organization of an institution through the creation of a dividing wall among coworkers, causing poor performance, even resignation, and disunity within the organization body.Discussion of conflicts in organizational behavior is very crucial because there will be a conflict in every organization; hence, to overcome the conflict, we need to understand some issuesin order to deal and cope with the conflict well.

The performance of the organization requires an optimal level of conflcit because it is widely assumed that without a conflict, there will be no chance to bring success into the organization. Therefore, it is necessary to manage the conflict so that the conflict can be maintained at a certain level (optimal) in order to create a conducive situation within the organization and improve the quality of work. The main purpose of the organizatin is to achieve something. This "something" is a goal, and it can not be achieved by self-employed individuals. It can only be fulfilled efficiently through the group efforts.

\section{Literature Review}

\subsection{Definition of Conflict}

According to Robbins [3], the existence of conflict in organizations is determined by the perception of individuals and groups. If they fail to realize that there has been a conflict within the organization, there is no conflict then.Conversely, should they perceive that there is a conflict in the organization, the conflict then becomes a reality. Stoner and Wankel [4] stated that organizational conflict is a mismatch between two or more members of the organization, arising from the fact that they have to share in obtaining scarce resources, job activities or due to their different statuses, goals, values or perceptions.

Organizations recognize the need to coordinate the formal patterns of interaction of the organizational members. 
Moreover, the organizational structure determines how the task will be shared, who reports to whom, and the formal patterns of coordination and interaction to be followed. As stated by Robbins [2] an organizational structure has three components: (1) complexity; (2) formalization and (3) centralization. Complexity considers the degree of differentiation that exists within the organization, including the degree of specialization or level of division of labor, organizational hierarchy and to what extent organizational units are dispersed. Formalization, looking to what extent an organization relies on rules and procedures to regulate the behavior of its members.

In general, the organizations operate with minimum standardized guidelines, and consider where the decision-making lies in order to be centralized within an organization. Problems are poured into the top management and appropriate action is then chosen; or the decisions are scattered down in the hierarchy but the realdecisions remain at the top management

Furthermore, Gibson, Ivancevich and Donelly suggests that conflicts within organizations arise as a result of communication problems, personal relationships, and organizational structures. Conflict can normally happen at any time and considered as a natural event and social reality occurring in the institutional process. Conflict is not an objective and real phenomenon, but it exists in the minds of the people involved in the conflict. So in dealing with conflict, a good leader is expected to be empathetic, understand the situation as perceived by the perpetrators of the conflict, and the most important element is persuasion, which is a subtle persuasion by giving good reason and prospect in order to successfully convince the perpetrators.

\subsection{The Causes of the Conflict}

According to Robins [3], conflict emerges because of the antecedent conditions. The condition, also called a source of conflict, consists of three categories, namely: communication, structure, and personal variables.

Communication, poor communication in the sen-se of communication that creates misunderstanding between the parties involved can be a source of conflict. That semantic difficulties, insufficient information exchange, and disruption in communication channels are a barrier to a good communicatio-

on and could create a conflict.

Structure, the term structure in this context is used to describe: size (group), degree of specialization given to group members, clarity of jurisdiction (work area), compatibility between member goals and group goals, leadership style, reward system and degree of dependence among groups. Research shows that group size and degree of specialization are the variables that encourage conflict, the larger the group and the more specialized the activity, the greater the possibility of the conflict.

Personal variables, other potential sources of the conflict are personal factors including: the value system of each individual, the characteristics of personality that make the individual unique and different from the other. The fact reveals that certain types of personality, such as emotional, anxious, tense, frustrated, and hostile, are considered as a real conflict. Should we fail to deal with the conflict immediately, it then could lead the involved parties to attack, threat, riot and other negative acts either verbally or physically.

The same opinion is expressed by Handoko [1], arguing the causes of the conflict are: (1)Communication, where misunderstandings are strongly related to sentences, incomprehensible language, or ambiguous and incomplete information; (2) Structures, i.e. interdepartmental power struggles with conflicting interests or judgment systems, competition 
for limited resources, or the interdependence of two or more working people to achieve their goals. (3) The personal matter, which is the discrepancies of an individual's personal goals or personal values with the behaviors played in their positions, and differences in values or perceptions.

Kreitner and Kinichi [5] stated that there are 12 factors causing the conflict, namely: (1) incompatibility of the personality of the value system; (2) unclear or overlapping work limits; (3) competition for limited resources; (4) insufficient information or communication exchanges; (5) interdependence in work; (6) organizational complexity; (7) unclear or unreasonable rules, standards of work, and policies; (8) unreasonable job deadlines that are difficult to fulfill; (9) collective decision-making; (10) decision-making through consensus; (11) unfulfilled expectations and (12) fail to resolve and conceal the conflict. Further, Stoner and Freeman (1989) argue that the causes of conflict are: (a) shared resources, (b) differences in goals, (c) interdependencies of work activities, (d) differences in values or perceptions, and (e) individual styles and organizational ambiguities.

\section{Methods}

The diagnosis of conflict in this paper will be presented from a continuum view model of Greenhalgh [6], whose explanation is as follows:

a. Problems in question. If the issue of conflict is a matter of principle, then the conflict is difficult to solve, because sacrificing principles is viewed as sacrificing personal integrity. Once the principal issues are linked, the involved parties try to argue that the views of the other side are wrong. If such a thing happens, then the form of intervention that can be done is to ask all parties to acknowledge that they understand the views of each other, though still believe in their own views. This way is more likely for all parties to advance in the negotiation process, rather than remain in their respective positions.

b. The bet size, the greater the value at stake in the debate, the more difficult the conflict is solved. For example, the acquisition policy (data recording and then processed through the compiler) which the leader deems harmful to his position. Such leaders are subjective-minded and perceive the stakes are very high. He, therefore, will try desperately to oppose the acquisition process. Hence, in this case it takes a persuasive approach by delaying the settlement, so that all parties become less emotional.It is better to be done during the postponement period so that each side can reevaluate the issue at stake and try to be objective in their judgment.

c. The interdependence of the involved parties, the parties involved in a conflict can find out themselves in a series of "zeroes" interdependence to "positively". Mutual reliance amounting to zero is the perception that if a party obtains something from the interaction process, then it means the sacrifice of another party. The positive dependence of each other is should both parties equally benefit from the interaction process. A zero-sized relationship makes conflicts difficult to solve because this relationship focuses narrowly on personal gains, rather than on the acquisition of both parties through cooperation and problem-solving. If that happens then both parties must be persuaded to consider how they can benefit from one situation.

d. Continuity of interaction, the dimension of continuity of interaction relates to the time horizon in which all parties see themselves relating to each other. If they visualize interactions that occur as long-term interactions or something that is continuously 
connected, then the conflicts that occur will be more easily resolved. Conversely, if interaction is seen as a short-term relationship then the conflict will be difficult to be solved. So the parties involved must be persuaded to realize that their relationship does not stop here, or when the conflict occurs, but there will be another continuous relationship in the future.

e. Structure of the involved parties. Conflicts are easier to resolve should one party has a strong leader who can unite his followers to accept and execute an agreement. If a weak leader is involved in a conflict, the agreed outcome may be hindered by those who may dislike some of the contents of the agreement.

f. Third party involvement, people tend to be emotionally involved in conflict. Such involvement can lead to some influences, viz. perception can be broken, irrational thought processes and arguments emerge, resulting in unwarranted stance, broken communication, and personal attacks arise. Such influences cause conflict to be difficult to be solved. Facing such a situation, the role of a neutral third party is indispensable. Neutral third parties will be more acceptable to the parties involved, because they prefer the evaluation of others rather than in the evaluation of the opposing party. The more authoritative, powerful, trustworthy, and neutral third-party, the more likely the parties involved in the conflict to control their emotion.

g. Conflict Progress, it is difficult to resolve the conflict if all parties involved are not ready for a reconciliation. If each party feels they are the most disadvantaged, then the conflict is difficult to be solved. So the important thing to do is to persuade the parties involved in order to make both of them suffering from the conflict. The involved parties should be brought in the same position so that they are willing to volunteer and take part in resolving the conflict.

\section{Discussions}

The following table is presented the model of conflict diagnosis based on Continent view:

\begin{tabular}{|c|c|c|}
\hline Dimensions & Difficult Solution & Easy Solution \\
\hline The questionable problems & Principle issues & Shared issues \\
\hline The bet size & Large & Small \\
\hline $\begin{array}{l}\text { The interindependence of the } \\
\text { involved parties }\end{array}$ & Zero & Positive Number \\
\hline Interaction Continuity & Single Transaction & Long term relationship \\
\hline $\begin{array}{l}\text { Structure of the involved } \\
\text { parties }\end{array}$ & $\begin{array}{l}\text { Formless or fragmented, } \\
\text { with weak leaders }\end{array}$ & Integrated with strong leaders \\
\hline Third party involevement & No neutral third party & $\begin{array}{l}\text { Trusted, strong, dignified, } \\
\text { respected and neutral }\end{array}$ \\
\hline $\begin{array}{l}\text { The progress of the conflict is } \\
\text { seen }\end{array}$ & $\begin{array}{l}\text { Uneven, one party feels } \\
\text { more harmed }\end{array}$ & $\begin{array}{l}\text { The parties have harmed each } \\
\text { other }\end{array}$ \\
\hline
\end{tabular}




\subsection{Conflict Management}

Dealing with the conflict through affective approach should know the ability of ourselves and those who have conflict. Spiegel cited in Juanita [7] explains there are five actions in the conflict management:

1. Competing, namely: actions taken when self-interest is preferred above the interests of others. This choice of action can be successful if the situation requires quick decisionmaking.

A winning-losing situation will definitely occur in this action.

2. Avoiding conflict, this action is taken should one party wants to avoid conflict both physically and psychologically. Avoiding conflicts can be done if each side tries to cool the atmosphere or temporarily freezes the conflict.

3. Accommodations, namely: It happens when one party surrenders and sacrifices some of its own interests or the other party gets benefits from the conflict situation. This action is often referred to as self sacrifying behavior. The consideration between personal interests and good relationships is the main point here.

4. Compromise, i.e.: actions taken by both parties to understand each other and feel that maintaining good relations is strongly needed. Each side will sacrifice some of its interests to get a win-win solution.

5. Collaboration, namely: create a win-win solution by working together.

Kreitner and Kinichi (1995), also stated there are five conflict management styles, in which the model is intended to address dysfunctional conflicts within the organization. This model illustrates five different styles of conflict management. On the vertical axis, it is describing the side of other-oriented problem-solving (concern for others), and on the horizontal axis depicts the side of self-oriented problem-solving (concern for self). The combination of these two variables produces five conflict management styles: integrating, obliging, dominating, avoiding, and compromising, as shown in the figure below:

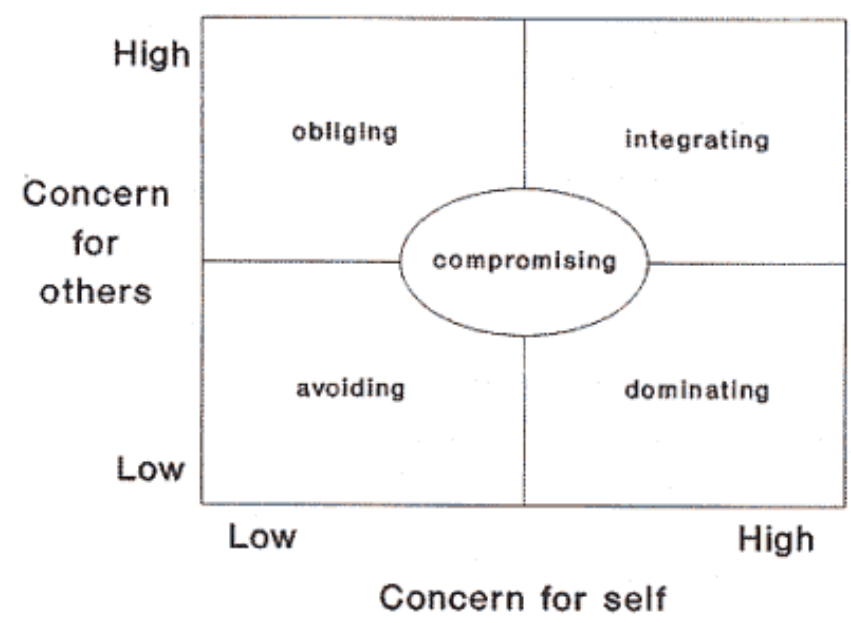

Fig. 1 Styles of Handling Interpersonal Conflict 
Integrating, in this style, the stakeholders jointly identify problems encountered, then seek, consider and choose alternative solutions to solve the problems. This style is suitable for solving complex issues particularly caused by misunderstanding

Obliging, in accordance with its position in the above picture, someone who is more focused on efforts to satisfy the other than himself. This style is also often called smoothing, because it seeks to reduce the differences and emphasize the similarity and togetherness among the involved parties.

Dominating, Dominating, namely: a high self-orientation, and low concern for the interests of others. This style is often called forcing because it uses formal legality in solving the problem. This style is suitable if unpopular ways are implemented in problem solving; problems that have been solved are not very important, and the time to make decisions is short. However, this approach is not suitable for dealing with the issues requiring participation of those involved.

Avoiding, which is avoidance tactics, suitable for solving trivial problems, or if the costs incurred for confrontation far higher than the benefits gained. This style is not suitable for solving the difficult problems. This style can be used if we face a confusing or ambiguous situation.

Compromising, this style places a person in a moderate position, which equally blends between his own interests and the interests of others. This is the approach of giving and receiving approaches from the parties involved. Compromising is suitable for dealing with the issues involving parties with different goals but have the same power.

The above models are just one of many models that can be chosen in the conflict management. Yet, what model is chosen depends on several factors, including: (1) the background of the conflict; (2) categories of the involved parties in the conflict; (3) the complexity of the problem to be solved; and (4) organizational complexity

\section{Conclusion}

From above explanation, it can be seen that conflict inevitably arises in the workplace. The role of the leader is crucial for overcoming the conflict, managing it flexibly so that the daily work rhythm is not disturbed.Research proves that the leader spends 80 percent of his total time working on verbal interaction with others, where 20 percent of his time is dealing with conflict, so that the leader may be the first party to the conflict, either a mediator or a third party whose role resolve conflicts among other parties affecting the organizations and individuals involved in the organization they lead.

It can be concluded that a leader must be able to play various management strategies in dealing with conflicts such as: (1) inviting people in conflict with higher goals. (2) looking for common ground and meeting members in conflict.This technique seeks to find the similarities between parties involved in the conflict. It tries to look for similarities in differences since we can be in different rhythms, but we will remain on the same scale. (3) Changing the nature of the people in conflict is very difficult, but it is an effective long-term conflict management. As the leaders, we have to invite the organization member slowly to change his behavior, pay more attention patiently to him, guide him until finally able to become a good institution member .(4). Changing the structure is used when the conflict always blame each other, and (5) using power, this is the most ancient way for conflict management. When a person in 
conflict does not want to end the conflict, a leader then has to use the power to overcome the conflict. For example by dismissing him from office, or do a mutation of office.

From all the above descriptions, The most important part of the leadership is able to create a competition, namely the use of power associated with the duties of its members through efforts to increase motivation among staff, resulting in a healthy competition and can work together. If the parties of the conflict work together to resolve the conflict, then the conflict can be resolved satisfactorily

\section{References}

[1] T. H. Handoko, "Manajemen, Edisi 2, Yogyakarta: BPFE UGM, Cet.” Ke-9, 1995.

[2] S. P. Robbins, Organization Theory: Structures, Designs, And Applications, 3/e. Pearson Education India, 1990.

[3] S. Robbins, Organizational Behavior. Concepts, Controversies, and Applications. USA: Prentice-Hall International Editions, 1996.

[4] J. A. F. Stoner and C. Wankel, Management. London: Prentice Hall International Inc., 1986.

[5] R. Kreitner and A. Kinicki, "Organizational Behavior, Printed in The United State of America: Richard D,” Irwin Inc, vol. 159, 1995.

[6] L. Greenhalgh, "Menangani Konflik," in Memimpin Manusia, A. D. Timpe, Ed. Jakarta: Gramedia, 1999.

[7] S. Juanita, "Manajemen konflik dalam suatu organisasi.” USU Digital Library, 2010. 